\title{
The effect of uncorrected ametropia on ocular torsion induced by changes in fixation
}

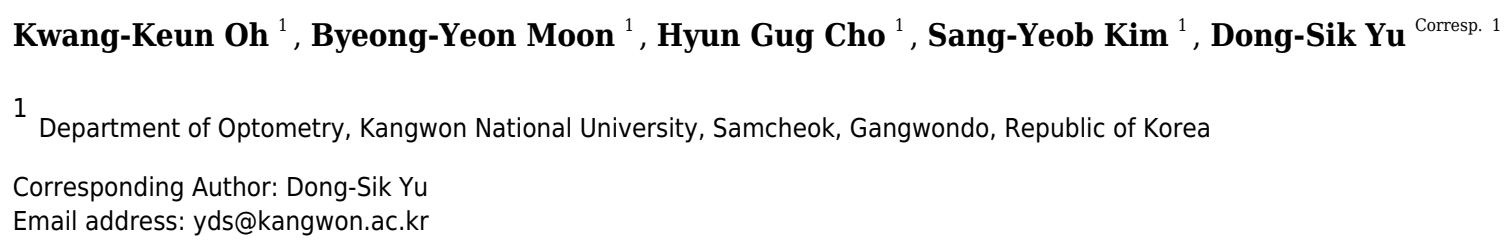

Background and Objective. Ocular torsion, the eye movements to rotating around the line of sight, has not been well investigated regarding the influence of refractive errors. The purpose of this study was to investigate the effect of uncorrected ametropia on ocular torsion induced by fixation distances. Methods. Seventy-two subjects were classified according to the type of their refractive error, and ocular torsion of the uncorrected eye was compared based on changes induced by different fixation distances. Ocular torsion was measured using a slit-lamp biomicroscope equipped with an ophthalmic camera and a half-silvered mirror. Results. In all groups, excyclotorsion values increased as the fixation distance decreased, but the myopia and astigmatism groups had larger amounts of ocular torsion than the emmetropia group. In addition, as the amount of uncorrected myopia and astigmatism increased, the amount of ocular torsion increased. Conclusion. Since the amount of ocular torsion caused by a change to a shorter fixation distance was larger when the refractive error was uncorrected, we suggest that ametropia should be fully corrected in patients frequently exposed to ocular torsion due to changes in fixation distance. 


\section{The effect of uncorrected ametropia on ocular torsion} 2 induced by changes in fixation

3

4

5 6

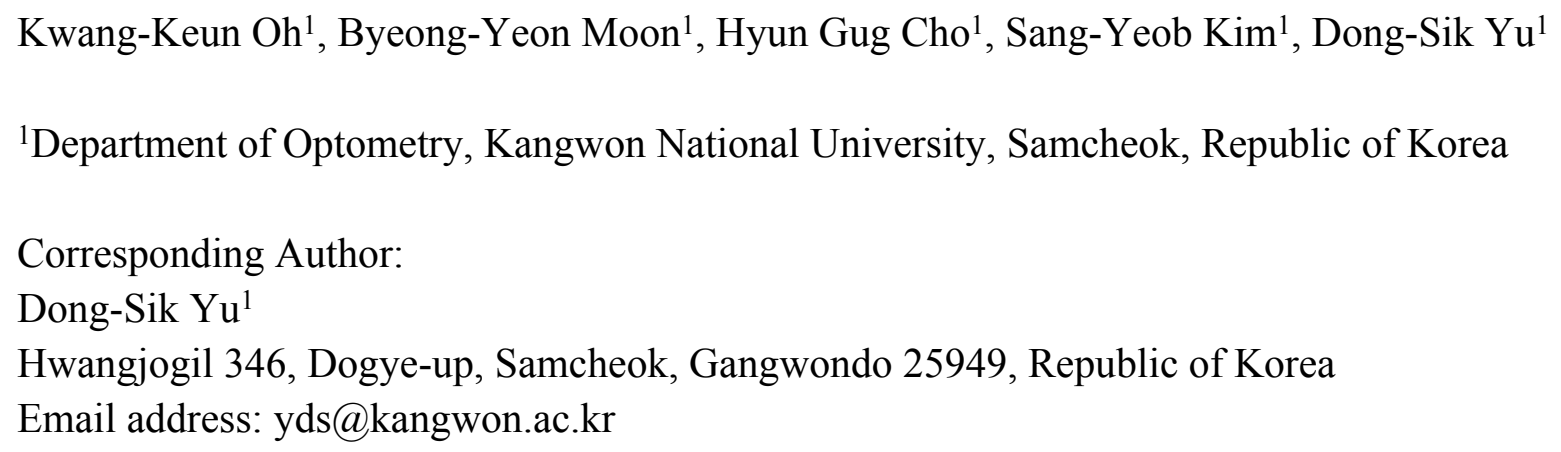

\section{ABSTRACT}

Background and Objective. Ocular torsion, the eye movements to rotating around the line of sight, has not been well investigated regarding the influence of refractive errors. The purpose of this study was to investigate the effect of uncorrected ametropia on ocular torsion induced by fixation distances.

Methods. Seventy-two subjects were classified according to the type of their refractive error, and ocular torsion of the uncorrected eye was compared based on changes induced by different fixation distances. Ocular torsion was measured using a slit-lamp biomicroscope equipped with an ophthalmic camera and a half-silvered mirror.

Results. In all groups, excyclotorsion values increased as the fixation distance decreased, but the myopia and astigmatism groups had larger amounts of ocular torsion than the emmetropia group. In addition, as the amount of uncorrected myopia and astigmatism increased, the amount of ocular torsion increased.

Conclusion. Since the amount of ocular torsion caused by a change to a shorter fixation distance was larger when the refractive error was uncorrected, we suggest that ametropia should be fully corrected in patients frequently exposed to ocular torsion due to changes in fixation distance.

\section{INTRODUCTION}

For clear visual perception, the retinal correspondence of both eyes prevents diplopia and enables stereoscopic vision. When moving the fixating object, the image of the retina moves quickly causing disturbances to the image. Therefore, eye movement is required for stable binocular retinal correspondence (van Rijn, van der Steen \& Collewijn, 1994). Eye movement is divided into three components: horizontal, vertical, and torsional movements (van Rijn, 1994). Ocular torsion, also known as rotation, is divided into excyclotorsion and incyclotorsion for outward and inward rotation, respectively, above the vertical meridian of the cornea (Sheiman \& Wick, 2014). 
40

41

42

43

44

45

46

47

48

49

50

51

52

53

54

55

56

57

58

59

60

61

62

63

64

65

66

67

68

69

70

71

72

73

74

75

76

77

78

79

Ocular torsion may occur as a compensatory movement that stabilizes the image of the retina in an environment such as in response to a head tilt (Schworm et al., 2002; Ko et al., 2011). This ocular counter-roll is generated by the vestibular ocular reflex (Schworm et al., 2002) and may be caused by signal imbalances of the vertical semicircular canals, but it is mainly induced by the action of the otolith organs (De Graaf, Bos \& Groen, 1996).

The ocular torsion can also occur with a static posture based on the distance of the fixation target (Allen, 1954; Enright, 1980). Ocular torsion in static posture occurring without tilting of the head or body is one of the factors that change the astigmatic axis between distant and near fixation (Leonard Werner \& Press, 2002). Scobee (1952) reported that the astigmatic axis changed in $77 \%$ of 247 examined subjects when the fixation was moved from a distant to a near point, and reported that it changed up to $10^{\circ}$. Although the rate of change in the astigmatic axis is large, the prescription rate for symptom relief is actually small. In the study by Joo \& Sim (2007), 837 (52.3\%) out of 1598 eyes showed changes of more than $10^{\circ}$ in the astigmatic axis. There are several factors that temporary change the distant and near axis of astigmatism. These factors include accommodation (Joo \& Sim, 2007; Hughes, 1941; O’brien \& Bannon, 1948), size of the pupil (Chikako, Yoshiko \& Ikuko, 2004; Asharlous et al., 2016; Noh et al., 2014), and the excyclotorsion effect of near vision (Allen, 1954; Leonard Werner \& Press, 2002; O’brien \& Bannon, 1948). Changes in the axis of astigmatism occurring at distant and near distance can affect the visual acuity. Visual acuity, stable fixation and eye movement have a great influence on the visual perception (MartinezConde, Macknik \& Hubel, 2004). There are several previous studies on visual perception and eye movements (Westheimer \& McKee, 1975; Gegenfurtner, 2016; Ibbotson \& Krekelberg, 2011); however, relatively few studies have examined among ocular torsion. The study by van Rijn, van der Steen \& Collewijn (1994) suggests that the instability of ocular torsion mainly affects the periphery of the retina. Therefore, they reported that studies of torsional movements are relatively few compared to horizontal and vertical movements. Baskaran et al (2019) reported less torsional vergence amplitude in myopes than in emmetropes. Moreover, in several previous studies, the uncorrected refractive error resulted in unstable fixation (Ko, Snodderly \& Poletti, 2016; Yu et al., 2017; Wahl S et al., 2019); when the stimulus of fixation was weak, the amount of ocular torsion increase (Choi et al., 2006). These previous studies indicate that uncorrected ametropia may affect ocular torsion.

Since ocular torsion induced by changes in fixation distance will influence the astigmatic axis and affect visual acuity and subjective symptoms, quantitative ocular torsion angle measurement is important. There are several methods for measuring ocular torsion. An indirect ophthalmoscope (Madigan \& Katz, 1992), video and digital camera (Bos \& de Graaf, 1994; Ong \& Haslwanter, 2010; Felius et al., 2009), slit-lamp biomicroscope (Jethani et al., 2010), and fundus photography are used to measure ocular torsion. However, there is no standardized approach. Among the techniques for measuring ocular torsion, the most commonly used method is fundus photography (Jethani et al., 2010; Williams \& Wilkinson, 1992; Rosenbaum \& Santiago, 1999; Kothari et al., 2005). However, since the distance of the target is fixed in fundus photography, as well as in the above-mentioned methods, it is difficult to assess ocular torsion induced by various fixation 
80

81

82

83

84

85

86

87

88

89

90

91

92

93

94

95

96

97

98

99

100

101

102

103

104

105

106

107

108

109

110

111

112

113

114

115

116

117

118

119

distances. In the present, fundus photography has a fixation target fixed inside and outside, or there is no fixation target (Panwar et al., 2015). Therefore, the amount of change in ocular torsion for a specific range of fixation distance cannot be measured. To measure this effect, we thought that specular reflection may be useful. If the fixation distance is shorter than 5-6 m, specular reflection is a method that is often used for subjective or objective refraction in practice (Andrew \& Caroline, 2007). In addition, in the case of simple myopia or hyperopia without astigmatism, the measurement of ocular torsion induced by a change in the fixation distance is difficult since there is no reference marker for rotation, unlike in astigmatism. However, we expected that ocular torsion in eyes without astigmatism can be measured using crypts on iris images. Using slit-lamp biomicroscopy and a half-silvered mirror, it may be possible to measure ocular torsion at any fixation distance.

The purpose of this study was to investigate the influence of uncorrected ametropia on ocular torsion induced by changes in fixation distance using crypts on iris images taken by slit-lamp biomicroscopy with a half-silvered mirror.

\section{MATERIALS AND METHODS}

\section{Paricipants}

A total of 72 college students (42 men, 30 women, mean age: $23.07 \pm 1.87$ years) without ophthalmic and vestibular diseases participated in this study. Among the subjects, there were 12 subjects with emmetropia, 57 subjects with myopia, and 3 subjects with hyperopia. None of the subjects had a history of strabismus or ocular surgery, as well as a history of disorders affecting the cornea or iris. The amplitude of accommodation using push-up method was conducted to exclude the instability of fixation at near owing to an accommodative dysfunction. The mean accommodation of subjects participating in this study was $10.84 \pm 2.35 \mathrm{D}$, and there were no subjects with accommodative dysfunction such as insufficiency or excess of accommodation and insufficiency of accommodation facility. In addition, it was confirmed that there was no dysfunction in the extraocular muscle and eye movement by performing the extraocular motility test on all subjects. The subjects with amblyopia were excluded from this study. This study was approved by the Institutional Review Board of Kangwon National University (IRB approval number: KWNUURB-2020-06-007-001) and adhered to the tenets of the Declaration of Helsinki. All participants provided written informed consent.

\section{Experimental protocol}

The procedure of this study is shown in Figure 1. After determining the refractive error of the study participants by subjective refraction using a manual phoropter (Phoropter 11625B; Reichert, USA), the iris images of the subjects were taken with a slit-lamp biomicroscope (SL-D701; Topcon, Japan) equipped with an ophthalmic camera (DC-4; Topcon, Japan) and a half-silvered mirror (Figure 2). The iris images were photographed three times at $16 \times$ magnification at a fixation distance of $5 \mathrm{~m}, 3 \mathrm{~m}$, and $40 \mathrm{~cm}$, and images with the most distinctive features, such as iris crypts, 
120 were analyzed using the ImageJ program (version 1.52a, National Institutes of Health, USA) (NIH,

121

122

123

124

125

126

127

128

129

130

131

132

133

134

135

136

137

138

139

140

141

142

143

144

145

146

147

148

149

150

151

152

153

154

155

156

157

158

159

2011). The fixation target was point target, and an iris image was taken in a binocular fixating condition. The diameter of the point target was $2.5 \mathrm{~cm}$ (visual angle of 0.29 degrees at $5 \mathrm{~m}$ and 0.35 degrees at $40 \mathrm{~cm}$ ). In order to exclude the effect of convergence that occurs as the near fixation distance, the specific image (Figure 3 ) was attached to the computer monitor, and the camera was moved slightly inward to keep the front of the pupil as much as possible. In the iris images, the iris crypts of the upper pupil were used as a reference point, and the iris crypts of the lower portion of the pupil were connected through the pupil center as much as possible, and a horizontal line was drawn to measure the angle. Ocular torsion was calculated as the difference between the angle at the 5-m fixation distance (reference point) and the angle at the other fixation distances ( $3 \mathrm{~m}$ or 40 $\mathrm{cm}$ ), as shown in Figure 4. The ocular torsion measurement method used in this study was introduced in the previous study and was reported to be suitable for measuring the ocular torsion (Oh et al., 2021).

The determined ocular torsion angle was analyzed according to the type and amount of ametropia. Referring to previous studies, emmetropia was within $\pm 0.50 \mathrm{D}$ (Shim, Shim \& Joo, 2006), whereas myopia was divided into a low group ( $-3.00 \mathrm{D}$ or below), a middle group $(-3.25$ D to -6.00 D), and a high group (over -6.25 D) (Chebil et al., 2015; Kapadia \& Wilson, 2000). Astigmatism was analyzed by dividing the study population into a $-1.00 \mathrm{D}$ or less group and a -1.25 D or more group (Villegas, Alcón \& Artal, 2014).

\section{Data analysis}

All the data collected were analyzed using IBM SPSS statistics software (version 24.0; IBM Corp., USA). To confirm the change of ocular torsion induced by fixation distance, the paired samples ttest with Bonferroni post-hoc, which is a parametric test, was performed. In addition, MannWhitney $\mathrm{U}$ test, which is a non-parametric test, was conducted for comparisons between the emmetropia and myopia groups. Kruskal-Wallis test for non-parametric analysis of variance was used for the comparative analysis between the ocular torsion angle and groups of ametropia. Pearson's correlation test determined the correlation between the amount of ametropia and ocular torsion. A p-value of $\leq 0.05$ was considered significant in this study.

\section{Results}

\section{Participants characteristics}

Their mean refractive power was $-3.17 \pm 2.97 \mathrm{D}$ for spherical equivalent and $-0.86 \pm 0.75 \mathrm{D}$ for cylindrical errors. A detailed analysis of the participant's refractive errors revealed that, the range of refractive error was $-0.16 \pm 0.21 \mathrm{D}$ in 12 participants (mean age: $22.67 \pm 1.72$ years) with emmetropia, and the range of refractive error was $-1.79 \pm 1.26 \mathrm{D}$ in 8 participants (mean age: $23.13 \pm 1.73$ years) with simple myopia. There were 24 participants (mean age: $22.88 \pm 1.80$ years) with an astigmatism amount of $1.00 \mathrm{D}$ or less, and the range of refractive error was $-4.36 \pm 2.55 \mathrm{D}$. The number of participants with an amount of astigmatism $1.25 \mathrm{D}$ or greater was 25 (mean age: $23.16 \pm 1.62$ years), and, the range of refractive error was $-5.02 \pm 2.69 \mathrm{D}$. The mean lateral phoria

PeerJ reviewing PDF | (2021:03:59094:1:0:NEW 28 Jun 2021) 
160

161

162

163

164

165

166

167

168

169

170

171

172

173

174

175

176

177

178

179

180

181

182

183

184

185

186

187

188

189

190

191

192

193

194

195

196

197

198

199

measured by the Maddox rod test was $1.78 \pm 4.20$ and $5.67 \pm 7.19$ prism diopter $(\Delta)$ exophoria at distant and near, respectively, and the mean vertical phoria was $0.22 \pm 1.17 \Delta$ hypophoria (for the right eye as a reference) at both distance and near. Cyclophoria was excluded in all study subjects using the Double Maddox rod test.

\section{Comparison of ocular torsion at fixation distances}

The mean ocular torsion values measured at fixation distances of $40 \mathrm{~cm}$ and $3 \mathrm{~m}$ are shown in Table 1. In both eyes, as the fixation distance decreased, the excyclotorsion increased $(p<0.001$ for both eyes, paired t-test). The mean difference in excyclotorsion between the right eye and the left eye was $0.05^{\circ}$ at $40 \mathrm{~cm}$ and $0.07^{\circ}$ at $3 \mathrm{~m}$, and the left eye had a higher rotation tendency than the right eye, but this difference was not statistically significant $(p=0.738$ at $40 \mathrm{~cm}, p=0.500$ at $3 \mathrm{~m}$, paired t-test). In the present study, a dominance of the right eye was observed in 53 subjects (73.6\%), and a left dominant eye was present in 19 subjects (26.4\%).

Figure 5 shows the mean excyclotorsion of the dominant and non-dominant eye induced by different fixation distances. The dominant eye had lower mean excyclotorsion values at both 40 $\mathrm{cm}$ and $3 \mathrm{~m}$ than the non-dominant eye but did not show a significant difference $(\mathrm{p}=0.470$ at 40 $\mathrm{cm}, \mathrm{p}=0.577$ at $3 \mathrm{~m}$, paired $\mathrm{t}$-test). Therefore, the analysis according to the type of ametropia was based on the dominant eye.

\section{Difference of ocular torsion between myopia and emmetropia}

In all groups of defined ametropia types, the mean ocular torsion increased with decreasing fixation distance. In the hyperopic group, the ranges of mean excyclotorsion at $40-\mathrm{cm}$ and $3-\mathrm{m}$ fixation distances were $1.65-2.46^{\circ}$ and $1.12-1.28^{\circ}$, respectively, but the number of subjects was too small (3 subjects), so they were excluded from further analyses in this study. Therefore, Table 2 shows only the changes in ocular torsion at different fixation distances in the emmetropic and myopic groups, excluding the hyperopic group. There was no significant difference in the mean ocular torsion between the emmetropia and myopia groups at both 40-cm and 3-m fixation distances ( $\mathrm{p}$ $=0.062$ at $40 \mathrm{~cm}, \mathrm{p}=0.178$ at $3 \mathrm{~m}$, paired t-test), but the myopia group showed a slightly larger excyclotorsion than the emmetropia group.

\section{Ocular torsion according to the amount of myopia}

Figure 6 shows the analysis of the mean ocular torsion according to the amount of myopia at different fixation distances. The mean excyclotorsion values at the fixation distances of $40 \mathrm{~cm}$ and $3 \mathrm{~m}$ in the myopia of $-3.00 \mathrm{D}$ or less group $(\mathrm{n}=22)$ were $1.31 \pm 0.63^{\circ}$ and $0.72 \pm 0.52^{\circ}$, respectively. In the myopia group of -3.01 to $-6.00 \mathrm{D}(\mathrm{n}=20)$, the mean excyclotorsion values were $1.82 \pm 0.94^{\circ}$ and $1.03 \pm 0.56^{\circ}$, respectively, and $2.56 \pm 0.81^{\circ}$ and $1.42 \pm 0.89^{\circ}$, respectively, in the myopia of $-6.01 \mathrm{D}$ or higher group $(\mathrm{n}=15)$. The mean excyclotorsion increased as the amount of myopia increased at both $40-\mathrm{cm}$ and $3-\mathrm{m}$ fixation distances ( $\mathrm{p}<0.001$ at $40 \mathrm{~cm}, \mathrm{p}=0.015$ at $3 \mathrm{~m}$, KruskalWallis test). In addition, there was a significant correlation between the amount of myopia and the ocular torsion angle at a $40-\mathrm{cm}$ fixation distance $(\mathrm{r}=-0.320, \mathrm{p}=0.006, \mathrm{y}=1.18-0.15 \times)$, but no 
200

201

202

203

204

205

206

207

208

209

210

211

212

\section{3}

214

215

216

217

218

219

220

221

222

223

224

225

226

227

228

229

230

231

232

233

234

235

236

237

238

239

significant correlation at the $3-\mathrm{m}$ fixation distance $(r=-0.225, \mathrm{p}=0.057, \mathrm{y}=0.69-0.08 \times)$.

\section{Ocular torsion according to myopic astigmatism}

Figure 7 shows the changes in ocular torsion according to the amount of astigmatism at 40-cm and 3 - $\mathrm{m}$ fixation distances. The mean excyclotorsion in the non-astigmatism group $(\mathrm{n}=20)$ was $1.41 \pm$ $0.74^{\circ}$ and $0.81 \pm 0.53^{\circ}$ at $40-\mathrm{cm}$ and $3-\mathrm{m}$ fixation distances, respectively, $1.52 \pm 0.86^{\circ}$ and $0.87 \pm$ $0.69^{\circ}$ in the $-1.00 \mathrm{D}$ or less group ( $\left.\mathrm{n}=24\right)$, and $2.19 \pm 0.92^{\circ}$ and $1.21 \pm 0.73^{\circ}$ in the $-1.25 \mathrm{D}$ or higher group $(\mathrm{n}=25)$. As the amount of astigmatism increased, the mean excyclotorsion also increased; however, only the 40-cm fixation distance showed a significant difference $(p=0.008$, Kruskal-Wallis test). As a result of the correlation analysis between the amount of astigmatism and ocular torsion, there was a significant correlation in both 40-cm and 3-m fixation distances ( $\mathrm{r}$ $=-0.440, \mathrm{p}=0.001, \mathrm{y}=1.41-0.39 \times$ at $40 \mathrm{~cm} ; \mathrm{r}=-0.288, \mathrm{p}=0.030, \mathrm{y}=0.81-0.21 \times$ at $3 \mathrm{~m})$.

\section{DISCUSSION}

In this study, we measured ocular torsion induced by varying fixation distances and analyzed it according to the type of ametropia. Our main finding was that in shorter fixation distance, no statistically significant difference between the emmetropia group and the myopia group was observed; however, the angle of ocular torsion was larger as the amount of myopia or astigmatism increased.

Eye movements comprise horizontal, vertical, and torsional movements. Ocular torsion is caused by head tilt, among other stimuli. We anticipated that ocular torsion without a head tilt would be the result of a change in fixation distance, and our findings showed that the shorter the fixation distance, the more excyclotorsion occurred. Ocular torsion occurs depending on the fixation distance (Allen, 1954; Leonard Werner \& Press, 2002). In a previous study on ocular torsion induced by varying fixation distances (Allen, 1954), it was reported that ocular torsion does not occur when performing horizontal conjugate movements, but excyclotorsion can be observed during horizontal disjunctive (i.e., convergence) or elevation movements. This action is related to the activation of the third cranial nerve nucleus stimulating the medial rectus muscle and the extraocular muscles (superior rectus, inferior rectus, inferior oblique) innervated by this cranial nerve (Allen, 1954). Therefore, it has been reported that the main action of the superior and inferior rectus muscles is neutralized, and excyclotorsion occurs due to the influence of the inferior oblique muscles (Mays et al., 1991). Due to this action, Allen \& Carter (1967) recommended that excyclotorsion should be added to the near reflex (accommodation, convergence, myosis) that occurs during near fixation.

Our results showed that ocular torsions were excyclotorsions of $1.76-1.81^{\circ}$ for $40 \mathrm{~cm}$ and $0.97-1.04^{\circ}$ for $3 \mathrm{~m}$. The mean pupillary distance of the subjects participating in this study was $61.93 \mathrm{~mm}$, and when the convergence angle for the $40-\mathrm{cm}$ fixation was calculated from this, a value of approximately $7.74^{\circ}$ (half of $15.48^{\circ}$ ) was obtained. Landolt (1876) reported that an excyclotorsion angle of $3.4^{\circ}$ was shown at a convergence angle of $15^{\circ}$. Referring to this, at a convergence angle of $7.5^{\circ}$, an excyclotorsion angle of $1.7^{\circ}$ can be estimated. In the study by Allen

PeerJ reviewing PDF | (2021:03:59094:1:0:NEW 28 Jun 2021) 
$240 \&$ Carter (1967) using a reflex camera for subjects with unknown refractive errors, an ocular 241 torsion angle of $4.30^{\circ}$ was observed for a convergence angle of $18^{\circ}$ at $0^{\circ}$ elevation angle, and it 242 was reported that an ocular torsion angle of $0.24^{\circ}$ occurred at a $1^{\circ}$ convergence angle. Applying 243 our results to this study of Allen and Carter, the estimated excyclotorsion was approximately $0.23^{\circ}$ 244 at a 40-cm fixation distance, very similar to that reported by Allen and Carter. Another study on 245 excyclotorsion associated with convergence in monkeys reported an ocular torsion angle of $1.05^{\circ}$ 246 at an $18.2^{\circ}$ convergence angle, which is very different from the present study (Mays et al., 1991). 247 Such differences in subjects and measurement methods could account for the similarities and 248 differences seen in our results compared to previous studies.

249 In the current study, the amount of ocular torsion also increased as the amount of myopia 250 increased. Ocular torsion that occurs in eyes with uncorrected myopia will change the astigmatic 251 axis, and it is thought that the larger the amount of uncorrected myopia, the greater the amount of 252 astigmatic axis changes. In previous studies on myopia and fixation stability (Zhu et al., 2019), it 253 was reported that myopia led to eye movements due to unstable retinal images, and increased eye 254 movements were observed in myopia compared to emmetropia. In addition, Choi et al. (2006) 255 reported that ocular torsion occurred less often in a stable fixation or stronger fixation state. Based 256 on these previous studies, it is thought that more ocular torsion will occurs due to unstable retinal 257 image, and it is expected that the amount of ocular torsion in the myopia group is larger than that 258 in the emmetropia group. It has been reported that patients with high myopia have poor fixation 259 and generate eye movements such as microsaccades, tremor, and drift during fixation (Ko, 260 Snodderly \& Poletti, 2016; Yu et al., 2017). Therefore, it is expected that patients with high myopia 261 or astigmatism will experience discomfort and subjective symptoms due to changes in the 262 astigmatic axis when under- or uncorrected.

263 In our results, uncorrected astigmatism increased the amount of ocular torsion induced by 264 changes in fixation distance. Ozulken \& Ilhan (2019), who studied the relationship between 265 astigmatism and ocular torsion before and after photorefractive keratectomy, reported that high 266 astigmatism before surgery was related to large ocular torsion, and this also affected postoperative 267 measurements. In another study, it was suggested that changing the power and axis of astigmatism 268 decreased the quality of the retinal image (Pujol et al., 1998). Therefore, under- or uncorrected 269 astigmatism power and axis will reduce the quality of the retinal image, and it is thought that the 270 larger the amount of uncorrected astigmatism, the greater the amount of ocular torsion required to 271 stabilize the inferior retinal image.

272 In the results of this study, the shorter the fixation distance, the more excyclotorsion occurred, 273 and the amount of excyclotorsion increased more when myopia and astigmatism were not 274 corrected. Changes in the astigmatic axis caused by ocular torsion will result in decreased visual 275 acuity, discomfort, fatigue, and various subjective symptoms. These will be more severe as the 276 amount of uncorrected astigmatism increases. In addition, it is expected that an increase in 277 unnecessary ocular torsion will potentially cause a small amount of cyclophoria. Wick \& Ryan 278 (1981) reported that the range of normal cyclophoria at a distance of $6 \mathrm{~m}$ was approximately 0.75 $279 \pm 1.15^{\circ}$, which differs from the ocular torsion angle caused by uncorrected ametropia at a fixation 
280

281

282

283

284

285

286

287

288

289

290

291

292

293

294

295

296

297

298

299

300

301

302

303

304

305

306

307

308

309

310

311

312

313

314

315

316

317

318

319

distance of $40 \mathrm{~cm}$ in the present study. Howe (1907) implied that the small amount of excyclophoria at near fixation distance were observed in just $25 \%$ of the study subjects and probably would not have a clinically affect. However, if the amount of uncorrected ametropia is large, the amount of ocular torsion angle also increases; so it is thought that full correction should be achieved for ametropia. In uncorrected astigmatism, the change in the astigmatic axis due to ocular torsion is expected to cause symptoms similar to cyclophoria in severe cases. Cyclophoria induces subjective symptoms like headaches, burning eye sensations, restless fatigue, slow reading speed, and missing letters within a line when reading (Sheiman \& Wick, 2014). In a study evaluating the change in the astigmatic axis and quality of the retinal image (Pujol et al., 1998), it was reported that the in vivo eye, unlike the theoretical model eye, is somewhat corrected by aberration when the change in the astigmatic axis is small. However, there may be a limit for aberration-induced corrections in uncorrected cases with high amounts of myopia or astigmatism.

This study has several limitations. Among the recruited subjects, the number of subjects with hyperopia was too small. The standard of emmetropia applied in this study was $\pm 0.50 \mathrm{D}$, and only three subjects had $+0.75 \mathrm{D}$ or higher. Therefore, the analysis of the hyperopia group was limited. Moreover, because there were only three subjects with an against-the-rule astigmatic axis and six subjects with an oblique astigmatic axis, the analysis related to the astigmatic axis was limited. Thus, further studies on hyperopia and the astigmatic axis should be conducted. Moreover, in the present study, uncorrected ametropia was not compared with fully corrected ametropia of the same participant, but with emmetropia. However, corrected ametropia is similar in visual function to that of emmetropia (Roch-Levecq et al, 2008), indicating that this should not limit the comparison between the ametropia and emmetropia groups. Another limitation is vergence. In this study, in order to minimize the effect of vergence, participants who were not included in the normal criteria were excluded from this study by conducting the vergence test. Nevertheless, vergence may affect fixation, limiting accurate ocular torsion measurement.

\title{
CONCLUSIONS
}

Summarizing the results of this study, when the distance changes from distant $(5 \mathrm{~m})$ to near (40 $\mathrm{cm}$ or $3 \mathrm{~m}$ ) fixation, excyclotorsion occurred. The amount of excyclotorsion between the emmetropia group and the myopia group was similar, but as a result of dividing the myopia group into three group, the amount of excyclotorsion increased as the amount of myopia increased. Similarly, excyclotorsion values were increased with increases in the uncorrected amount of astigmatism. This means that in cases with large amounts of uncorrected myopia or astigmatism, ocular torsion will occur during near-distance activities such as reading more pronounced than in fully corrected cases. Therefore, we suggest that a full correction should be performed to reduce changes in ocular torsion due to ametropia, especially when working at near distance.

\section{ACKNOWLEDGEMENTS}

\author{
Not applicable.
}


320

321

322

323

324

325

326

327

328

329

330

331

332

333

334

335

336

337

338

339

340

341

342

343

344

345

346

347

348

349

350

351

352

353

354

355

356

357

358

359

\section{REFERENCES}

Allen MJ. 1954. The dependence of cyclophoria on convergence, elevation and the system of axes. American Journal of Optometry and Archives of American Academy of Optometry 31:297-307. DOI: 10.1097/00006324-195406000-00006

Allen MJ, Carter JH. 1967. The torsion component of the near reflex. American Journal of Optometry and Archives of American Academy of Optometry 44:343-349. DOI: 10.1097/00006324-196706000-00001

Andrew K, Caroline C. 2007. Clinical optics and refraction: A guide for optometrists, contact lens opticians and dispensing opticians, 1st Ed. London: Butterworth-Heinemann, 90-91.

Asharlous A, Hashemi H, Jafarzadehpur E, Mirzajani A, Yekta A, Nabovati P, Khabazkhoob M. 2016. Does astigmatism alter with cycloplegia? Journal of Current Ophthalmology 28:131-136. DOI: 10.1016/j.joco.2016.05.003

Baskaran AA, Britto T, Rajkumar S, Thomas PA, Nelson Jesudasan CA. 2019. Comparison of torsional amplitudes between emmetropes and myopes using after-image slides. Indian Journal of Ophthalmology 67:655-658. DOI: 10.4103/ijo.IJO_1663_18

Bos JE, de Graaf B. 1994. Ocular torsion quantification with video images. IEEE Transactions on Biomedical Engineering 41:351-357. DOI: 10.1109/10.284963

Chebil A, Jedidi L, Chaker N, Kort F, Limaiem R, Mghaieth F, Matri LE. 2015. Characteristics of astigmatism in a population of Tunisian school-children. Middle East African Journal of Ophthalmology 22:331-334. DOI: 10.4103/0974-9233/150635

Chikako H, Yoshiko HK, Ikuko T. 2004. Refraction at different diameters using the Nidek OPDScan. Journal of Refractive Surgery 20:S759. DOI: 10.3928/1081-597X-20040903-55

Choi HY, Kim EH, Lee SJ, Lambert SR. 2006. Ocular torsion according to fixation in fundus photography. Journal of American Association for Pediatric Ophthalmology and Strabismus 10:71. DOI: 10.1016/j.jaapos.2006.01.087

De Graaf B, Bos JE, Groen E. 1996. Saccular impact on ocular torsion. Brain Research Bulletin 40 40:321-326. DOI: 10.1016/0361-9230(96)00126-8

Enright JT. 1980. Ocular translation and cyclotorsion due to changes in fixation distance. Vision Research 20:595-601. DOI: 10.1016/0042-6989(80)90116-9

Felius J, Locke KG, Hussein MA, Stager DR jr, Stager DR Sr. 2009. Photographic assessment of changes in torsional strabismus. Journal of American Association for Pediatric Ophthalmology and Strabismus 13:593-595. DOI: 10.1016/j.jaapos.2009.09.008

Gegenfurtner KR. 2016. The interaction between vision and eye movements. Perception 45:1333-1357. DOI: https://doi.org/10.1177/0301006616657097

Howe L. 1907. Muscles of the eye, vol. 1. New York: Knickerbocker Press, 251-264.

Hughes WL. 1941. Change of axis of astigmatism on accommodation. Archives of Ophthalmology 26:742-749. DOI: 10.1001/archopht.1947.0087017002Ibbotson M, Krekelberg B. 2011. Visual perception and saccadic eye movements. Current Opinion in Neurobiology 21:553-558. DOI: 10.1016/i.conb.2011.05.012 
360

361

362

363

364

365

366

367

368

369

370

371

372

373

374

375

376

377

378

379

380

381

382

383

384

385

386

387

388

389

390

391

392

393

394

395

396

397

398

Ibbotson M, Krekelberg B. 2011. Visual perception and saccadic eye movements. Current Opinion in Neurobiology 21:553-558. DOI: 10.1016/i.conb.2011.05.012

Jethani J, Seethapathy G, Purohit J, Shah D. 2010. Mesuring normal ocular torsion and its variation by fundus photography in children between 5-15 years of age. Indian Journal of Ophthalmology 58:417-419. DOI: 10.4103/0301-4738.67060

Joo SH, Sim HS. 2007. A study for the change of astigmatism axis when the fixation point moved far distance to near distance. Journal of Korean Ophthalmic Optics Society 12:47-59.

Kapadia MS, Wilson SE. 2000. One- year results of PRK in low and moderate myopia: fewer than $0.5 \%$ of eyes lose two or more lines of vision. Cornea 19:180-184. DOI: 10.1097/00003226-200003000-00011

Ko BY, Choi JS, Kim KS, Choi H. 2011. Age and gender specific reference value of ocular torsion by using funduscope in Korean. Research in Vestibular Science 10:30-33.

Ko HK, Snodderly DM, Poletti M. 2016. Eye movements between saccades: measuring ocular drift and tremor. Vision Research 122:93-104. DOI: 10.1016/j.visres.2016.03.006

Kothari MT, Venkatesan G, Shah JP, Kothari K, Nirmalan PK. 2005. Can ocular torsion be measured using the slitlamp biomicroscope? Indian Journal of Ophthalmology 53:43-47. DOI: 10.4103/0301-4738.15284

Landolt. 1876. Handbuch der gesammten augenheilkunde, band 2. Leipzig, 660-692.

Leonard Werner D, Press LJ. 2002. Clinical pearls in refractive care. Boston: ButterworthHeinemann, 101-137.

Madigan WP Jr, Katz NN. 1992. Ocular torsion-direct measurement with indirect ophthalmoscope and protractor. Journal of Pediatric Ophthalmology and Strabismus 29:171174. DOI: 10.3928/0191-3913-19920501-10

Martinez-Conde S, Macknik SL, Hubel DH. 2004. The role of fixational eye movements in visual perception. Nature Reviews Neuroscience 5:229-40. DOI: 10.1038/nrn1348

Mays LE, Zhang Y, Thorstad MH, Gamlin PD. 1991. Trochlear unit activity during ocular convergence. Journal of Neurophysiology 65:1484-1491. DOI: 10.1152/jn.1991.65.6.1484

NIH (National Institutes Health, USA). 2011. Image $J$ ver 1.45. Available at http://imagej.nih.gov/ij/download.html (accessed 29 January 2019).

Noh YS, Kim SY, Moon BY, Cho HG. 2014. Change of refractive errors caused by corneal shape and pupil size. Journal of Korean Ophthalmic Optics Society 19:383-387. DOI: 10.14479/jkoos.2014.19.3.383

O'brien JM, Bannon RE. 1948. Concerning accommodative astigmatism. Clinical and Experimental Optometry 31:204-211. DOI: 10.1111/j.1444-0938.1948.tb06334.x

Oh KK, Moon BY, Cho HG, Kim SY, Yu DS. 2021. Measurement of ocular counter-roll using iris images during binocular fixation and head tilt. Journal of International Medical Research 49:1-11. DOI: $10.1177 / 0300060521997329$

Ong JK, Haslwanter T. 2010. Measuring torsional eye movements by tracking stable iris features. Journal of Neuroscience Methods 192:261-267. DOI 10.1016/j.jneumeth.2010.08.004 
399

400

401

402

403

404

405

406

407

408

409

410

411

412

413

414

415

416

417

418

419

420

421

422

423

424

425

426

427

428

429

430

431

432

433

434

435

436

437

438

Ozulken K, Ilhan C. 2019. Effects of cyclotorsion orientation and magnitude in eyes with compound myopic astigmatism on the compensation capacity of WaveLight EX500 photorefractive keratectomy. Korean Journal of Ophthalmology 33:458-466. DOI: https://doi.org/10.3341/kjo.2019.0042

Panwar N, Huang P, Lee J, Keane PA, Chuan TS, Richhariya A,Teoh S, Lim TH, Agrawal R. 2015. Fundus photography in the 21 st century-A review of recent technological advances and their implications for worldwide healthcare. Telemedicine and e-Health 22:198-208. DOI: $10.1089 / \mathrm{tmj} .2015 .0068$

Pujol J, Arjona M, Arasa J, Badia V. 1998. Influence of amount and changes in axis of astigmatism on retinal image quality. Journal of the Optical Society of America. A, Optics, Image Science, and Vision 15:2514-2521. DOI: 10.1364/josaa.15.002514

Roch-Levecq AC. Brody BL, Thomas RG, Brown SI. 2008. Ametropia, preschoolers' cognitive abilities, and effects of spectacle correction. Archives of Ophthalmology 126:252-258. DOI: 10.1001/archophthalmol.2007.36

Rosenbaum AL, Santiago AP. 1999. Clinical strabismus management, 1st Ed. Philadelphia: Saunders, 55-59.

Schworm HD, Ygge J, Pansell T, Lennerstrand G. 2002. Assessment of ocular counterroll during head tilt using binocular video oculography. Investigative Ophthalmology \& Visual Science 43:662-667.

Scobee R. 1952. The oculorotary muscles, 2nd ed. St. Louis: Mosby, 200-212.

Sheiman M, Wick B. 2014. Clinical management of binocular vision: heterophoric, accommodative, and eye movement disorders, 4th Ed. Philadelphia: Lippincott Williams \& Wilkins, 389-428.

Shim HS, Shim MS, Joo SH. 2006. A study of accommodative response on emmetropia. Journal of Korean Ophthalmic Optics Society 11:187-192.

van Rijn LJ. 1994. Torsional eye movements in humans. Rotterdam: Erasmus University, 1-8.

van Rijn LJ, van der Steen J, Collewijn H. 1994. Instability of ocular torsion during fixation: cyclovergence is more stable than cycloversion. Vision Research 34:1077-1087. DOI: 10.1016/0042-6989(94)90011-6

Villegas EA, Alcón E, Artal P. 2014. Minimum amount of astigmatism that should be corrected. Journal of Cataract \& Refractive Surgery 40:13-19. DOI: 10.1016/j.jcrs.2013.09.010

Wahl S, Dragneva D, Rifai K. 2019. The limits of fixation-keeping the ametropic eye on target. Journal of Vision 13:8. DOI: https://doi.org/10.1167/19.13.8

Westheimer G, McKee SP. 1975. Visual acuity in the presence of retinal-image motion. Journal of the Optical Society of America 65: 847-850. DOI: 10.1364/josa.65.000847

Wick B, Ryan JB. 1981. Clinical aspects of cyclophoria: definition, diagnosis, therapy. Journal of the American Optometric Association 53:987-995.

Williams TD, Wilkinson JM. 1992. Position of the fovea centralis with respect to the optic nerve head. Optometry and Vision Science 69:369-377. DOI: 10.1097/00006324-199205000-00006

Yu G, Yang M, Yu P, Dorris MC. 2017. Time compression of visual perception around microsaccades. Journal of Neurophysiology 118:416-424. DOI: 10.1152/jn.00029.2017 
439 Zhu X, He W, Zhang K, Zhang Y, Fan Q, Lu Y. 2019. Fixation characteristics in highly myopic 440 eyes: The Shanghai High Myopia Study. Scientific Reports 9:6502. DOI: 10.1038/s41598-019$441 \quad 42895-3$ 


\section{Figure 1}

\section{Flow chart for the ocular torsion of uncorrected refractive error.}

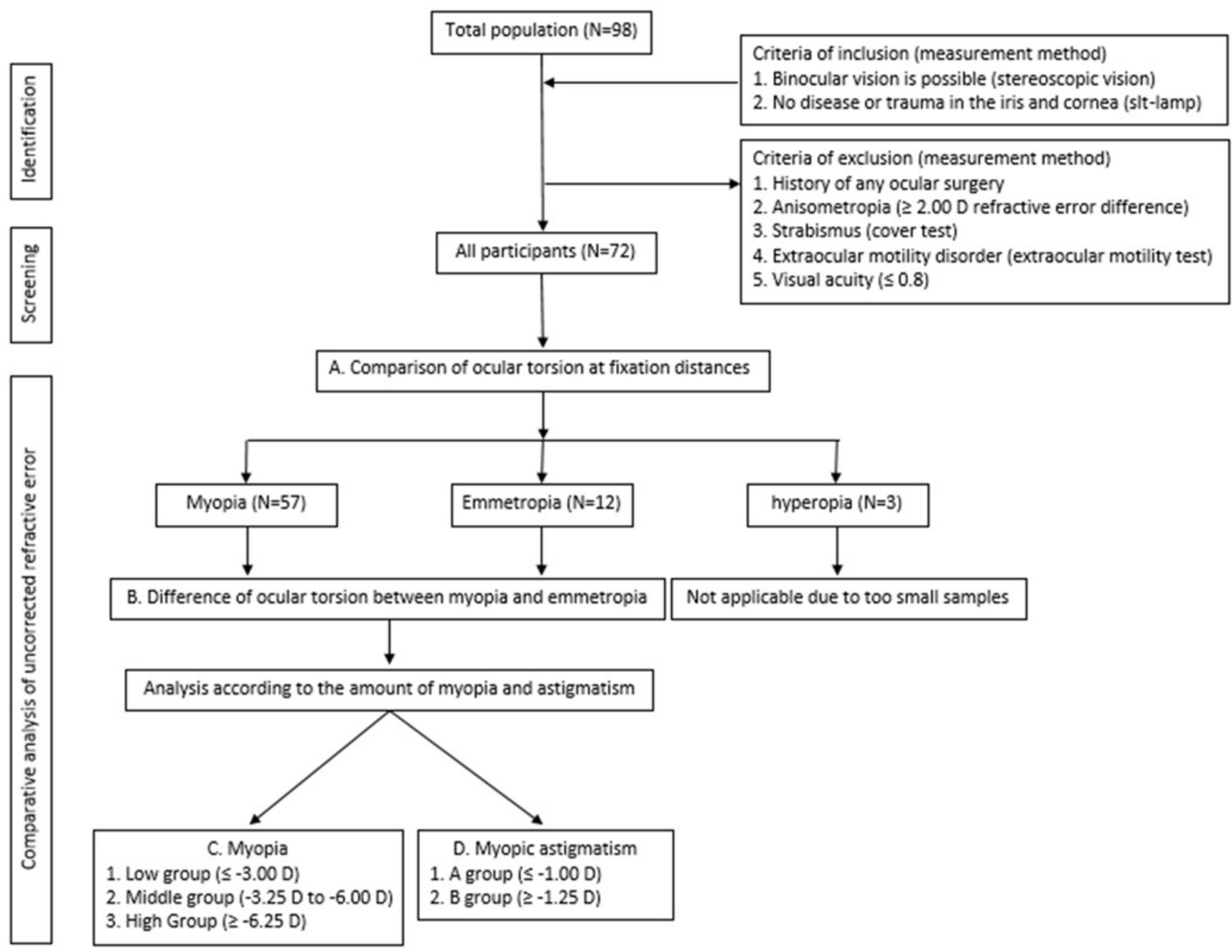


Figure 2

Slitlamp biomicroscope using a camera and a half-silvered mirror.

(A) View from the side. (B) View from above.

(A)

Plane mirror

(Forehead of subjects)

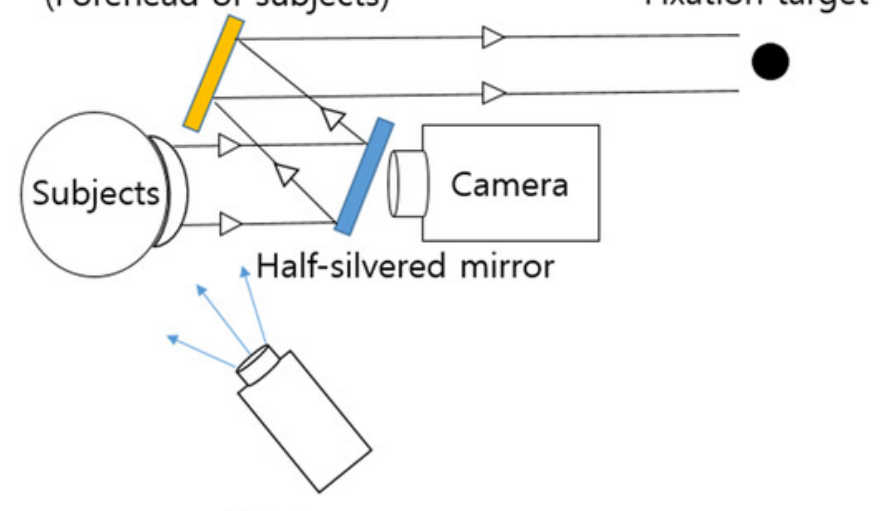

Light source
(B)

Fixation target

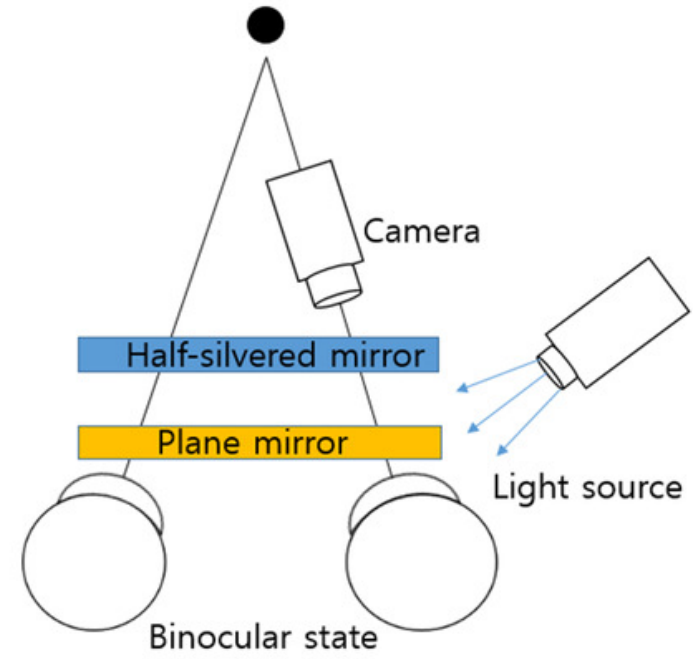




\section{Figure 3}

The specific image using on this study.

(A) The specific image. (B) The specific image attached to the monitor.
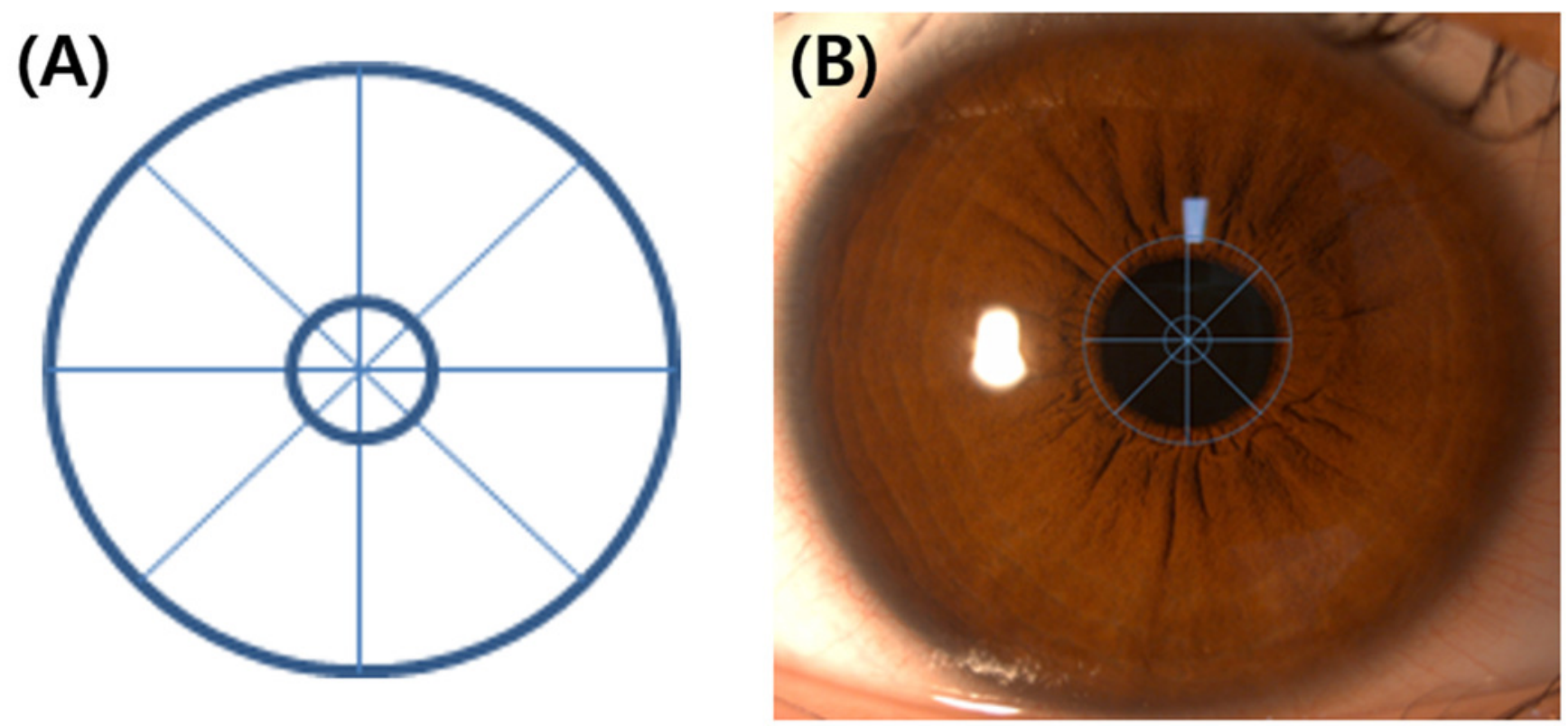


\section{Figure 4}

Ocular torsion of a left eye determined with ImageJ.

The fixation distances are $5 \mathrm{~m}$ (left image) and $40 \mathrm{~cm}$ (right image). In this case, ocular torsion is $1.731^{\circ}\left(97.157^{\circ}-95.426^{\circ}\right)$ excyclotorsion.

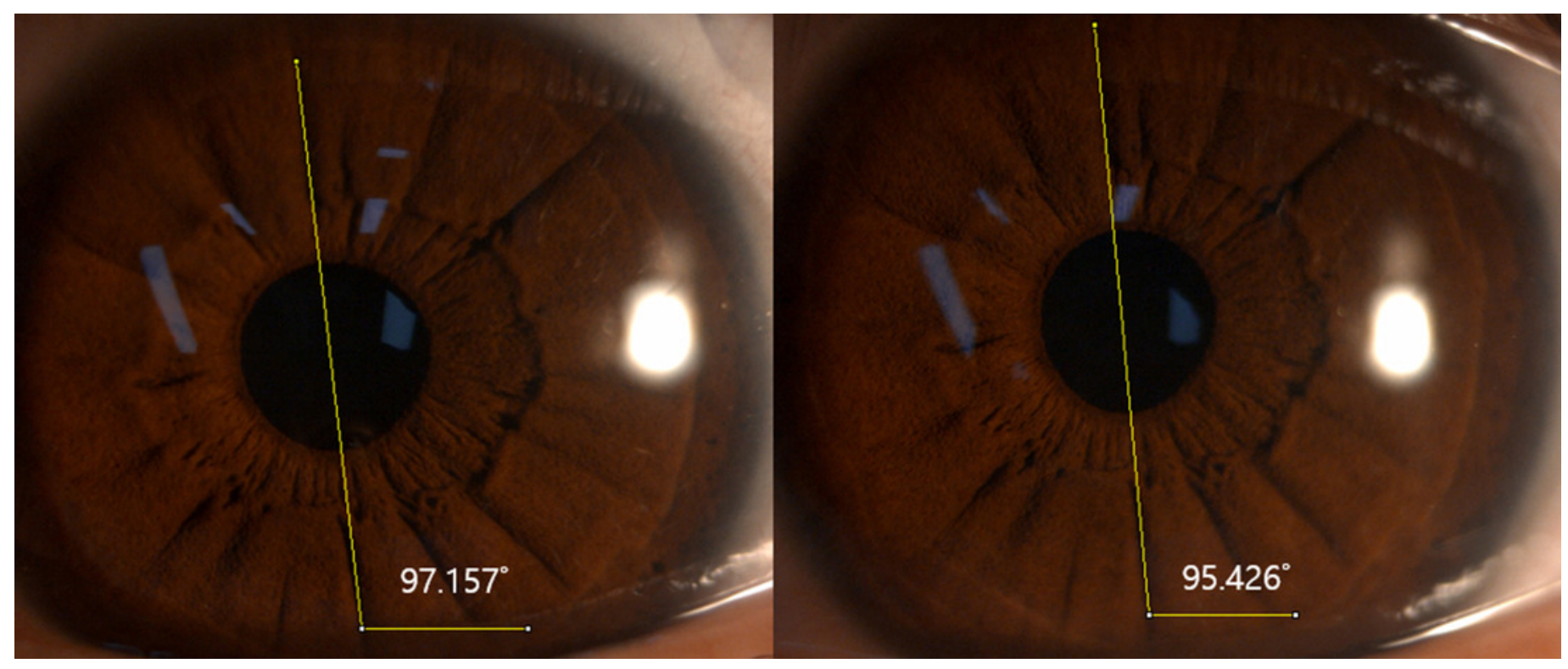


Figure 5

Comparison of the ocular torsion between the dominant and non-dominant eye at different fixation distances.

The number of subjects with the right dominant eye was 53, and the left dominant eye was 19.

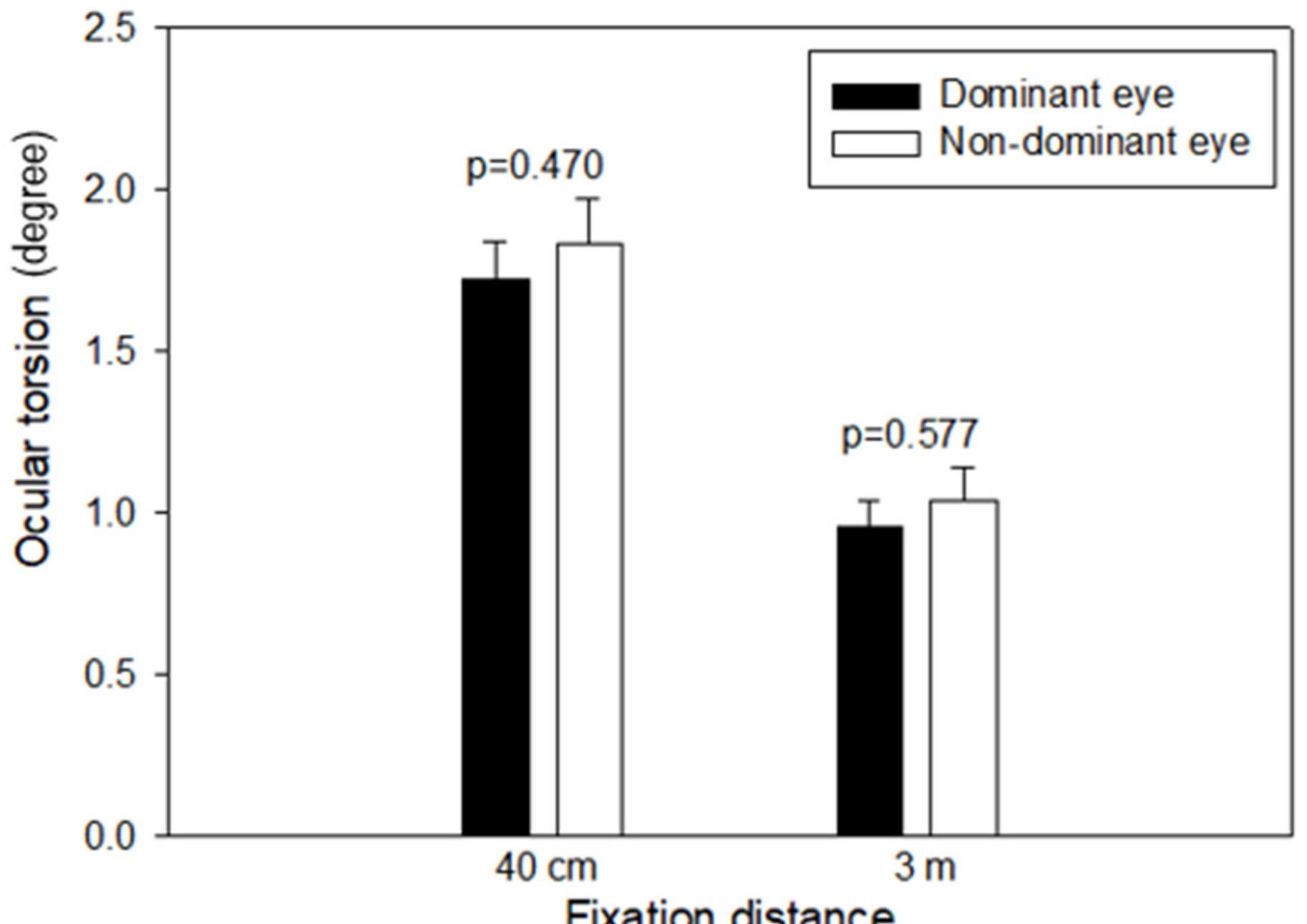


Figure 6

Mean ocular torsion according to the amount of myopia at different fixation distances.

Upper and lower lines indicate linear regression at $40 \mathrm{~cm}$ and $3 \mathrm{~m}$ fixation distance, respectively. 


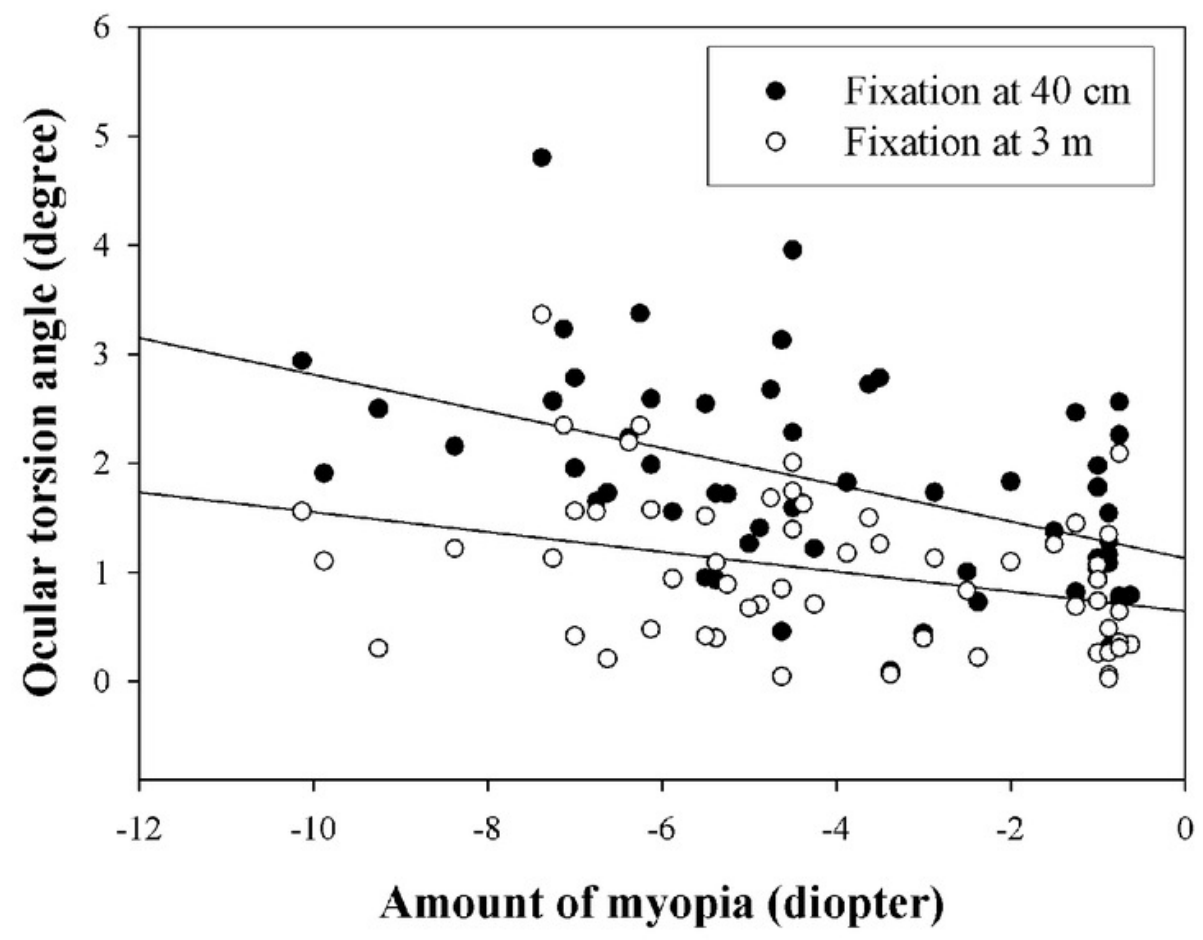




\section{Figure 7}

Mean ocular torsion according to the amount of astigmatism at different fixation distances.

Upper and lower lines indicate linear regression at $40 \mathrm{~cm}$ and $3 \mathrm{~m}$ fixation distance, respectively. 


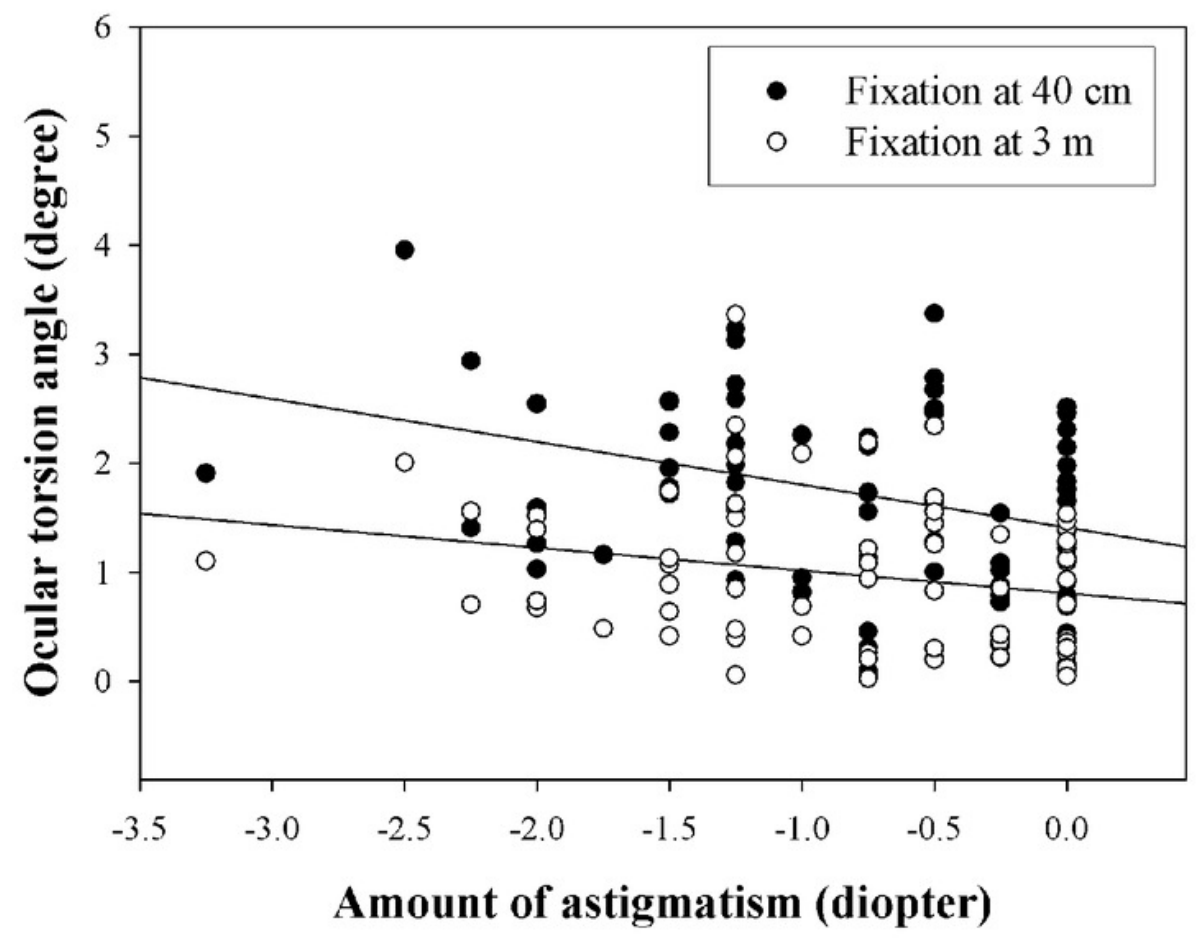




\section{Table 1 (on next page)}

Mean ocular torsion induced by different fixation distances. 


\begin{tabular}{c|c|c}
\hline Fixation distance & Right eye & Left eye \\
\hline $40 \mathrm{~cm}$ & $1.76 \pm 0.90^{\circ}$ & $1.81 \pm 1.21^{\circ}$ \\
\hline $3 \mathrm{~m}$ & $0.97 \pm 0.68^{\circ}$ & $1.04 \pm 0.88^{\circ}$ \\
\hline Mean difference & $0.79^{\circ}$ & $0.77^{\circ}$ \\
\hline Paired t-test $(p)$ & $<0.001$ & $<0.001$ \\
\hline $\mathrm{n}$ & 72 & 72 \\
\hline
\end{tabular}

1 
Table 2 (on next page)

Changes in ocular torsion at different fixation distances according to uncorrected myopia. 


\begin{tabular}{c|c|c|c}
\hline Fixation distance & $\begin{array}{c}\text { Emmetropia } \\
(\mathbf{n = 1 2})\end{array}$ & $\begin{array}{c}\text { Myopia } \\
(\mathbf{n = 5 7})\end{array}$ & $p^{\dagger}$ \\
\hline $40 \mathrm{~cm}$ & $1.26 \pm 0.78^{\circ}$ & $1.80 \pm 0.92^{\circ}$ & 0.062 \\
\hline $3 \mathrm{~m}$ & $0.74 \pm 0.70^{\circ}$ & $1.00 \pm 0.69^{\circ}$ & 0.178 \\
\hline Mean difference & $0.52^{\circ}$ & $0.80^{\circ}$ & - \\
\hline
\end{tabular}

1 Ocular torsion values were determined based on the dominant eye. The refractive state was analyzed with the 2 spherical equivalent. ${ }^{\dagger} p$-value for Mann-Whitney $\mathrm{U}$ test.

3 